\title{
L'hypercholestérolémie familiale. de la maladie au gène...
}

Le prix Nobel 1985 attribué à Michael S. Brown et Joseph L. Goldstein récompense une recherche à plus d'un titre exemplaire, notamment par l'importance médicale du sujet traité (les mécanismes de l'athérosclérose) et par l'ampleur et la diversité des méthodes mises en œuvre 13 ans durant. Débutant par des études de biologie cellulaire, se poursuivant par une analyse enzymologique et de chimie des protéines, les recherches de Brown et Goldstein ont abouti ces deux dernières années au clonage des gènes impliqués dans la régulation du métabolisme des lipoprotéines, à la détermination de leur structure et de leur contrôle, à la caractérisation enfin des anomalies génétiques en cause chez les malades atteints d'hypercholestérolémie familiale. En 1973, Brown et Goldstein découvrent que les lipoprotéines de faible densité (LDL) contenant du cholestérol estérifié se fixent à des récepteurs membranaires hautement spécifiques, présents sur la surface de toutes les cellules. Le complexe LDL-récepteur est ensuite internalisé et dissocié dans le cytoplasme. Le récepteur sera recyclé alors que la partie lipidique des LDL sera dégradée dans les lysosomes, libérant le cholestérol non estérifié. Ce dernier peut être réutilisé par la cellule ou, dans des cellules spécialisées, transformé en hormones stéroïdes ou en acides biliaires. En cas de non utilisation, le cholestérol s'accumule et la cellule réduit la synthèse de récepteurs des LDL, donc la captation de lipoprotéines. Elle bloque aussi la synthèse interne de cholestérol en réduisant la synthèse d'une enzyme essentielle de cette voie métabolique, l'HMGCoA-réductase.

Dans l'hypercholestérolémie familiale, la concentration des LDL est très élevée. A l'état hétérozygote (1/500 de la population des Etats-
Unis), cette affection entraine une athérosclérose précoce avec infarctus du myocarde à partir de 35 ans. La concentration des LDL y est double de la normale. A l'état homozygote, beaucoup plus rare $(1 / 1000000)$, les LDL sont augmentées environ 6 fois, et les malades meurent d'infarctus avant l'âge de 20 ans. La cause de la maladie est l'absence ou la réduction des récepteurs des LDL. Les LDL circulantes ne sont plus épurées, ce qui en augmente la concentration. Un autre mécanisme aggrave cette élévation des LDL : l'absence de captation du cholestérol des LDL déréprime la synthèse endogène de cholestérol, principalement en accroissant l'activité de l'HMGCoA-réductase. Les anomalies génétiques responsables des hypercholestérolémies familiales sont diverses; elles peuvent entrainer une absence ou une diminution de la synthèse des récepteurs, ou la synthèse de récepteurs non fonctionnels. En 1983, Brown et Goldstein entreprenaient le clonage des ARN messagers et des gènes codant pour le récepteur des LDL et pour l'HMG-CoA-réductase. La détermination de la séquence nucléotidique des deux gènes a permis d'en déduire la séquence complète en aminoacides des deux protéines, et de constater que le gène codant pour le récepteur des LDL avait été "construit" au cours de l'évolution par l'association d'exons existant déjà dans d'autres gènes : ceux du facteur de croissance EGF et du complément. Plusieurs gènes mutés de malades atteints d'hypercholestérolémie familiale étaient aussi clonés et analysés. Les mutations à l'origine de la maladie semblent très variées : délétions partielles, présence d'un codon stop dans un exon, décalage de phase de lecture de l'ARN. Enfin, la possession de "sondes d'ADN" a permis de déterminer le niveau du contrôle de la synthèse du récepteur des LDL et de l'HMG-CoA-réductase par le cholestérol : il est transcriptionnel dans les deux cas.

Cette dernière observation a d'importantes implications thérapeutiques : puisque le cholestérol inhibe la transcription du gène codant pour le récepteur, une déplétion en cholestérol (entraînée par exemple par le blocage du cycle entérohépatique des sels biliaires par la cholestyramine) devrait, chez les hétérozygotes, stimuler la transcription du gène restant et, par conséquent augmenter la synthèse des récepteurs. Malheureusement une telle déplétion déréprime aussi l'HMGCoA-réductase, et donc la synthèse endogène du cholestérol et la production de LDL. Cette dernière difficulté peut être surmontée grâce à l'existence d'inhiteurs compétitifs puissants de l'HMG-CoA-réductase, la Compactin et la Mevalonin. Cette association peut normaliser la concentration des LDL chez les hétérozygotes. Ces travaux expliquent également comment un régime riche en cholestérol va aboutir à l'accumulation de cholestérol dans le foie, donc à une réduction de la concentration membranaire en récepteur et à une augmentation des LDL circulantes, facteur de risque athérogène.

Voilà bien en effet une recherche exemplaire confortant notre position : les barrières entre praticiens et chercheurs sont d'ignorance et non d'intérêt scientifique...

A.K.

Brown MS, Goldstein J L. Fed Proc 1985,44 52-6o.

Lehrman M A, Goldstein J L, Brown M, et al. Cell 1985; 41 : 735-43.

Reynolds G A, Basu S K, Osborne T L, et al. Cell 1984; 38; 275-85.

Südhof T C, Goldstein J L, Brown M S, et al. Science 1985; $228: 81$ 5-22. 